\title{
Association between dietary patterns and the risk of metabolic syndrome among Lebanese adults
}

\author{
F. Naja $\cdot$ L. Nasreddine $\cdot$ L. Itani $\cdot$ N. Adra $\cdot$ \\ A. M. Sibai $\cdot$ N. Hwalla
}

Received: 29 June 2011/Accepted: 1 December 2011/Published online: 23 December 2011

(C) The Author(s) 2011. This article is published with open access at Springerlink.com

\begin{abstract}
Purpose The main objective of this study was to evaluate the association between dietary patterns and the metabolic syndrome (MetS) and its metabolic abnormalities among Lebanese adults, using data from a national nutrition survey. Methods A cross-sectional analysis involving adults aged $\geq 18$ years $(n=323)$ with no prior history of chronic diseases was conducted. Participants completed a brief sociodemographic and 61-item food frequency questionnaire. Anthropometric measurements and fasting blood samples were also obtained. The International Diabetes Federation criteria were used to classify study participants with the metabolic syndrome. Dietary patterns were identified by factor analysis. Multivariate logistic regression analysis was used to evaluate the associations of extracted patterns with MetS and its metabolic abnormalities.

Results Out of 323 participants, 112 (34.6\%) were classified as having MetS. Three dietary patterns were identified: "Fast Food/Dessert," "Traditional Lebanese," and
\end{abstract}

F. Naja and L. Nasreddine contributed equally to this manuscript.

F. Naja $\cdot$ L. Nasreddine $\cdot$ L. Itani · N. Adra $\cdot$ N. Hwalla $(\bowtie)$ Department of Nutrition and Food Sciences, Faculty of Agricultural and Food Sciences, American University of Beirut, Riad El-Solh, P.O.Box 11-0236, Beirut 1107-2020, Lebanon

e-mail: nahla@aub.edu.lb

F. Naja $\cdot$ L. Nasreddine $\cdot$ N. Adra $\cdot$ A. M. Sibai $\cdot$ N. Hwalla Members of the Public Health and Nutrition (PHAN) Research Group, American University of Beirut, Riad El-Solh, P.O.Box 11-0236, Beirut 1107-2020, Lebanon

A. M. Sibai

Department of Epidemiology and Population Health,

American University of Beirut, Riad El-Solh,

P.O.Box 11-0236, Beirut 1107-2020, Lebanon
"High Protein." Compared with participants in the lowest quintile of the Fast Food/Dessert pattern, those in the highest quintile had significantly higher odds for MetS (OR, 3.13; 95\% CI: 1.36-7.22) and hyperglycemia (OR, 3.81; 95\% CI: 159-9.14). Subjects with the highest intake of the High Protein pattern had an increased risk for hypertension (OR, 2.98; 95\% CI: 1.26-7.02). The Traditional Lebanese pattern showed no association with MetS or its components.

Conclusions The findings of this study demonstrate a positive association of the Fast Food/Dessert pattern with MetS and hyperglycemia among Lebanese adults. These results may guide the development of improved preventive nutrition interventions in this adult population.

Keywords Dietary pattern $\cdot$ Factor analysis $\cdot$ Metabolic syndrome $\cdot$ Lebanon

\section{Introduction}

The metabolic syndrome (MetS) refers to a cluster of cardiovascular and diabetes risk factors that identifies individuals at particularly high risk for these chronic diseases [1]. These risk factors include hyperglycemia, raised blood pressure, elevated serum triacylglycerols (TAG) levels, low high-density lipoprotein cholesterol levels, and obesity, particularly central adiposity [2]. In the Middle East region, the prevalence of MetS has increased significantly in recent years, and this increase has been attributed, for the most part, to rapid socioeconomic growth and change in lifestyle [3]. Among its neighboring countries, Lebanon-a small middle-income country on the Eastern shore of the Mediterranean sea-has unique characteristics that render the health of its population a complex 
challenge: a high urbanization rate $(87 \%)$, fast decline in fertility and mortality rates, and a growing trend toward survival in later life, coupled with westernization and changes in lifestyle. A recent review paper showed that Lebanon has one of the highest estimated prevalence of MetS among adults in the region (31.2\%) [4].

Several studies have been conducted underscoring the important role of dietary habits in influencing the risk of developing MetS, the majority of which, however, have focused on single nutrients or food items [5, 6]. This conventional approach has several limitations mainly the interaction between nutrients, confounding by foods/ nutrients not eaten and the problem of collinearity. To overcome these limitations, nutritional epidemiologists suggest studying dietary patterns as an alternative approach to evaluate diet-disease association [7]. This approach looks beyond the single nutrient or food and attempts to capture the broader picture of diet that is hypothesized to be linked to health and disease. Moreover, results from dietary patterns analyses are more helpful in disseminating diet-related messages to consumers that they may be more likely to adhere to rather than those related to single foods or nutrients [8].

Although few studies have investigated the association of dietary patterns with MetS in various populations, there is still no consensus as to which dietary patterns would confer the lowest risk of MetS [9-12]. In the East Mediterranean region, studies evaluating this association are scarce. Using data from a recent nation-wide populationbased survey of Lebanese adults, this study aims to identify and characterize the various dietary patterns among Lebanese adults and to examine the association of these dietary patterns with the risk of MetS and its various metabolic abnormalities. Findings from the study could inform prevention strategies as well as prognosis among subjects with high risk of MetS.

\section{Methods}

\section{Study population}

The data for this study were drawn from the nation-wide Nutrition and Non-Communicable Diseases Risk factors cross-sectional survey conducted in Lebanon between years 2008 and 2009. The sampling was random, multistage (by governate) and was based on the age-sex distribution of the Lebanese population [Living Conditions of households: The National Survey of Household Living Conditions 2004; Lebanese Republic Ministry of Social Affairs/Central Administration for Statistics/UNDP, pages 114-115]. Survey participants older than 18 years of age and with no chronic diseases were contacted to give blood samples $(n=1331)$. From these participants who were invited to participate, 323 subjects provided written consent and gave a blood sample (response rate: $24.3 \%$ ). The protocol was approved by the Institutional Review Board of the American University of Beirut, and all subjects gave informed consent for their participation.

\section{Data collection}

Data collection took place in the participants' homes by trained field workers, phlebotomists, and dietitians. Data collection procedures followed the WHO STEPwise approach to Surveillance (STEPS) [13] and included the following:

- Step 1 Questionnaire. Information about sociodemographic, lifestyle characteristics, and meal patterns was collected. The short version of the International Physical Activity Questionnaire (IPAQ) was used to assess physical activity among participants. Three categories of physical activity (low, moderate, and high) were assigned based on METS-min per week [14]. Dietary intake of participants was assessed by a 61-item food frequency questionnaire (FFQ) that measured food intake over the past year. For each food item listed on the FFQ, a standard portion size was indicated and five frequency choices were given. This FFQ was designed by a panel of nutritionists and included culture-specific dishes and recipes. It was tested on a convenient sample to check for clarity and cultural sensitivity. Daily gram intakes of food items, energy, and macronutrients intake of participants were computed using the food composition data base of the Nutritionist IV software [15]. The FFQ was administered by a trained dietitian.

- Step 2 Anthropometric measurements including weight, height, and waist circumference were taken using standardized techniques and calibrated equipments. Blood pressure was measured using a standard mercury sphygmomanometer, after participants were seated and rested for $5 \mathrm{~min}$.

- Step 3 Biochemical measurements. Blood samples were collected from after an overnight fast. Serum was centrifuged on site and shipped on dry ice to the American University of Beirut Laboratory. Levels of TAG, HDL-C, and glucose were measured by an enzymatic spectrophotometeric technique using Vitros 350 analyzer (Ortho-Clinical Diagnostics, Johnson \& Jhonson, 50-100 Holmers Farm Way, High Wycombe, Buckighamshire, HP12 4DP, United Kingdom). The inter-assay variation of measurements did not exceed 4\%. Quality control was performed within each run using standard performance verifier solutions provided by Ortho-Clinical Diagnostics. All samples were analyzed in duplicates, and the average value was used in statistical analysis. 
Definition of metabolic syndrome

The definition for MetS released by the International Diabetes Federation Task force on Epidemiology and Prevention was used in this study [2].

Dietary patterns derivation

For the purpose of the determination of dietary patterns, food items were grouped into 25 food groups based on similarities in ingredients, nutrient profile, and/or culinary usage ("Appendix 1"). Food items having a unique composition that differed from other groups (e.g. eggs, olives, and mayonnaise) were classified individually. The total consumption for each group was determined by summing the daily gram intake of each item within the group. Exploratory factor analysis was implemented to identify dietary patterns. The rotated factor loadings matrix was extracted (varimax rotation). The derived dietary patterns were labeled based on food groups having a rotated factor loading greater than 0.4. Factor scores were calculated by multiple regression and were categorized into quintiles based on the total sample distribution.

\section{Statistical analyses}

Frequencies, means, and standard deviations (SD) were used to describe various sociodemographic, lifestyle, anthropometric, and clinical characteristics of participants with and without MetS. Pearson's correlation coefficients were used to examine the association between dietary patterns and energy and energy-adjusted nutrient intakes. Energy adjustment was carried out using the regression residual method [16]. Multiple linear regression analyses were used to assess the correlates of the dietary patterns, with factor scores for each of the identified patterns as dependent variable and the sociodemographic and lifestyle characteristics as independent variables. The associations between dietary patterns and risk of MetS as well as the various metabolic abnormalities were assessed using multivariate logistic regression. $p$ for trend was performed using the median factor score for each quintile. All analyses were two tailed, and a $p$ value $<0.05$ was considered statistically significant. The Statistical Package for the Social Sciences was used for all computations [17].

\section{Results}

Overall prevalence of MetS in our study population was $34.7 \%$. Demographic, lifestyle, anthropometric, and clinical characteristics of survey participants with and without MetS are presented in table $1(n=323)$. There were significant differences between participants with and without MetS by age, sex, and marital status (Table 1). Participants with MetS had worse serum profiles (lower HDL and higher TAG and glucose serum concentrations), higher BMI, waist circumference, and blood pressure as compared to participants without MetS.

Factor analysis revealed three main dietary patterns: Fast Food/Dessert, Traditional Lebanese, and High Protein, which explained $13.11,9.71$, and $7.8 \%$ of the dietary intake variance, respectively (Table 2). Factor loading showed that the Fast Food/Dessert pattern was characterized by high intake of fast foods sandwiches including hamburger, chawarma, falafel in addition to pizzas, pies, desserts, carbonated beverages and juices, and mayonnaise. The Traditional Lebanese pattern consisted mostly of dairy products, olives, fruits, legumes, grains, eggs, vegetable oil, dried fruits, and traditional sweets. The High Protein pattern was characterized by high intakes of fish, chicken, meat, and low-fat dairy products. The factor loading matrix of these patterns is shown in Table 2.

Table 3 shows the associations between the factor scores of the three dietary patterns with energy and energyadjusted nutrient intakes as assessed by Pearson's correlation coefficients. Among the three patterns, the Fast Food/Dessert pattern had the strongest positive association with energy, fat, and saturated fat intakes $(r=0.66,0.19$, and 0.26 , respectively, $p<0.01$ ). As for the Traditional Lebanese pattern, the higher the scores, the greater were the intakes of fiber and omega 6 fatty acids $(r=0.31$ and 0.23 , respectively, $p<0.05$ ). Scores of the High Protein pattern displayed the highest positive correlations with intakes of proteins and cholesterol $(r=0.6$ and 0.28 , respectively, $p<0.05$ ).

Multiple linear regression models were applied to examine the associations between selected sociodemographic and lifestyle characteristics with the scores of the three patterns identified in this study (Table 4). The Fast Food/Dessert pattern was more adopted by younger adults and males, while the Traditional Lebanese pattern was more common among older subjects. The higher the crowding index, the higher were the scores of the Fast Food/Dessert pattern. Scores of both patterns showed a positive association with snack consumption per day. The High Protein pattern scores were positively associated with physical activity and the frequency of eating out per week.

Table 5 shows the association between the quintiles of the identified dietary patterns scores with MetS and its various metabolic abnormalities. Subjects belonging to the 5th quintile of the Fast Food/Dessert factor score had significantly higher odds of hyperglycemia (OR: 3.81, 95\% CI: 1.59-9.14). On the other hand, subjects belonging to 
Table 1 Demographic, lifestyle, anthropometric, and clinical characteristics of participants in the nutrition and non-communicable diseases survey who were included in this study $(n=323)$
Categorical variables are reported as absolute and relative frequencies $N(\%)$; continuous variables are reported as mean $\pm \mathrm{SD}$

${ }^{a} p$ value was derived from chisquare for categorical variables and from independent student $t$ test for continuous variables

b Crowding index was defined as the average number of people per room, excluding the kitchen and bathroom

\begin{tabular}{|c|c|c|c|}
\hline $\begin{array}{l}\text { Demographic and } \\
\text { lifestyle variables }\end{array}$ & $\begin{array}{l}\text { Participants } \\
\text { with } \\
\text { MetS }(n=112)\end{array}$ & $\begin{array}{l}\text { Paticipants } \\
\text { without } \\
\text { MetS }(n=211)\end{array}$ & Significance $^{\mathrm{a}}$ \\
\hline Age (years) & $42.83 \pm 15.34$ & $36.50 \pm 13.91$ & $p<0.001$ \\
\hline Sex & & & $X^{2}=9.994, p<0.05$ \\
\hline Males & $69(61.6)$ & $91(43.1)$ & \\
\hline Females & $43(38.4)$ & $120(56.9)$ & \\
\hline Marital status & & & $X^{2}=6.575, p<0.05$ \\
\hline Single & $32(28.6)$ & $91(43.1)$ & \\
\hline Married & $80(71.4)$ & $120(56.9)$ & \\
\hline Education & & & $X^{2}=11.469, p<0.05$ \\
\hline Less than complimentary & $58(51.8)$ & $69(32.7)$ & \\
\hline High school & $28(25.0)$ & $67(31.8)$ & \\
\hline University and Higher education & $26(23.2)$ & $75(35.5)$ & \\
\hline Family history of obesity & & & $X^{2}=0.298, p>0.05$ \\
\hline No & $67(59.8)$ & $119(56.7)$ & \\
\hline Yes & $45(40.2)$ & $91(43.3)$ & \\
\hline Smoking & & & $X^{2}=1.155, p>0.05$ \\
\hline No & $72(64.3)$ & $148(70.1)$ & \\
\hline Yes & $40(35.7)$ & $63(29.9)$ & \\
\hline Physical activity level & & & $X^{2}=1.180, p>0.05$ \\
\hline Low & $42(37.5)$ & $75(35.5)$ & \\
\hline Moderate & $25(22.3)$ & $39(18.5)$ & \\
\hline High & $45(40.2)$ & $97(46.0)$ & \\
\hline Crowding index ${ }^{\mathrm{b}}$ & $1.14 \pm 0.62$ & $1.11 \pm 0.55$ & $p>0.05$ \\
\hline Breakfast per week & $4.89 \pm 2.82$ & $4.93 \pm 2.75$ & $p>0.05$ \\
\hline Snack per day & $1.85 \pm 0.90$ & $1.85 \pm 0.97$ & $p>0.05$ \\
\hline Eating at TV per week & $2.72 \pm 3.14$ & $2.88 \pm 3.20$ & $p>0.05$ \\
\hline Eating out per week & $3.90 \pm 3.47$ & $3.68 \pm 3.44$ & $p>0.05$ \\
\hline \multicolumn{4}{|l|}{ Anthropometric and clinical characteristics } \\
\hline $\mathrm{BMI}(\mathrm{Kg} / \mathrm{m} 2)$ & $29.6 \pm 4.7$ & $25.3 \pm 4.6$ & $p<0.05$ \\
\hline$\%$ Overweight & $92(49.2)$ & $95(45.5)$ & $X^{2}=41.8 ; p<0.001$ \\
\hline$\%$ Obese & $46(41.4)$ & $30(14.4)$ & $X^{2}=29.4 ; p<0.001$ \\
\hline Triacylglycerols (mg/dl) & $194.0 \pm 86.5$ & $108.01 \pm 51.48$ & $p<0.05$ \\
\hline$\%$ Elevated serum triacylglycerols & $76(67.9)$ & $24(11.4)$ & $X^{2}=109.2 ; p<0.001$ \\
\hline HDL-C (mg/dl) & $44.2 \pm 12.1$ & $54.8 \pm 14.1$ & $p<0.05$ \\
\hline$\%$ Reduced HDL-C & $60(53.6)$ & $42(19.9)$ & $X^{2}=38.4 ; p<0.001$ \\
\hline Serum glucose (mg/dl) & $115.8 \pm 28.0$ & $97.0 \pm 16.3$ & $p<0.05$ \\
\hline$\%$ Elevated glucose & $88(78.6)$ & $60(28.4)$ & $X^{2}=74.1 ; p<0.001$ \\
\hline Mean systolic blood pressure (mm Hg) & $133.3 \pm 17.6$ & $119.2 \pm 13.2$ & $p<0.05$ \\
\hline Mean diastolic blood pressure $(\mathrm{mm} \mathrm{Hg})$ & $80.9 \pm 10.5$ & $74.3 \pm 9.0$ & $p<0.05$ \\
\hline$\%$ With hypertension & $77(68.8)$ & $53(25.1)$ & $X^{2}=57.9 ; p<0.001$ \\
\hline Mean waist circumference $(\mathrm{cm})$ & $97.1 \pm 11.8$ & $83.8 \pm 12.2$ & $p<0.05$ \\
\hline$\%$ Elevated waist circumference & $90(80.4)$ & $77(36.5)$ & $X^{2}=56.4 ; p<0.001$ \\
\hline
\end{tabular}

the 5th quintile of the High Protein pattern had significantly higher odds of hypertension compared to those in the lowest quintile(OR: 2.98, CI: 1.26-7.02). As for the risk of MetS, the odds were three times higher in the 5 th quintile of the Fast Food/Dessert compared to the 1st quintile (OR: 3.13; 95\% CI: 1.36-7.22).

\section{Discussion}

In this study population, we identified three major dietary patterns by means of factor analysis: Fast Food/Dessert, Traditional Lebanese, and High Protein. Consumption of the Fast Food/Dessert pattern was associated with an 
Table 2 Factor loading matrix for the three identified dietary patterns in the study population $(n=323)$

Factor loadings of $<|0.2|$ were not listed in the table for simplicity. Loadings $\geq 0.3$ are bolded

Table 3 Pearson's correlation coefficients of the association between dietary pattern scores with total energy and energyadjusted nutrient intakes

Nutrient intake was adjusted by the residual method [16]. Values are Pearson's correlation coefficients

* Correlation is significant at the 0.05 level

** Correlation is significant at the 0.01 level

\begin{tabular}{|c|c|c|c|}
\hline & \multicolumn{3}{|l|}{ Dietary patterns } \\
\hline & Fast food/dessert & Traditional Lebanese & High protein \\
\hline Hamburger & 0.76 & - & \\
\hline Chawarma & 0.72 & - & - \\
\hline Pizza and pies & $\mathbf{0 . 7 0}$ & - & - \\
\hline Falafel Sandwiches & 0.61 & - & - \\
\hline Desserts & 0.41 & 0.23 & - \\
\hline Carbonated beverages and juices & 0.40 & - & - \\
\hline Mayonnaise & 0.35 & - & - \\
\hline Butter & 0.22 & - & - \\
\hline Alcoholic beverages & 0.20 & - & - \\
\hline Dairy products-full fat & - & 0.58 & - \\
\hline Olives & - & 0.56 & - \\
\hline Fruits & -0.22 & 0.49 & 0.21 \\
\hline Legumes & & 0.47 & - \\
\hline Grains & 0.27 & 0.47 & - \\
\hline Eggs & 0.21 & 0.45 & - \\
\hline Vegetable oil & - & 0.43 & - \\
\hline Nuts and dried fruits & 0.27 & 0.40 & - \\
\hline Traditional sweets & - & 0.37 & - \\
\hline Vegetables & - & 0.34 & - \\
\hline Fish & - & - & 0.70 \\
\hline Chicken & 0.21 & - & 0.69 \\
\hline Meat & 0.22 & - & 0.60 \\
\hline Dairy products-low fat & - & -0.29 & 0.54 \\
\hline Breakfast cereals & - & - & 0.23 \\
\hline Hot drinks & - & - & - \\
\hline Percent variance explained by each pattern & 13.11 & 9.71 & 7.80 \\
\hline
\end{tabular}

\begin{tabular}{lccc}
\hline & \multicolumn{2}{l}{ Dietary patterns } & \\
\cline { 2 - 4 } & Fast food/dessert & Traditional Lebanese & High protein \\
\hline Total energy & $0.66^{* *}$ & $0.59^{* *}$ & $0.23^{* *}$ \\
Protein & $-0.18^{* *}$ & $-0.28^{* *}$ & $0.60^{* *}$ \\
Carbohydrates & -0.10 & 0.07 & $-0.12^{*}$ \\
Fat & $0.19^{*}$ & 0.07 & $0.04^{*}$ \\
Cholesterol & 0.05 & -0.03 & $0.28^{* *}$ \\
Saturated fat & $0.26^{* *}$ & -0.07 & -0.07 \\
Omega 6 fatty acids & -0.06 & $0.23^{* *}$ & $-0.13^{* *}$ \\
Fiber & $-0.31^{* *}$ & $0.31^{* *}$ & $0.19^{* *}$ \\
Alcohol & 0.11 & -0.05 & -0.06 \\
Sugars & $0.30^{* *}$ & -0.02 & $-0.12^{*}$ \\
\hline
\end{tabular}

increased risk of hyperglycemia and metabolic syndrome. A positive association between the High Protein pattern and hypertension was also found.

The Fast Food/Dessert dietary pattern was characterized by high intake of fast foods sandwiches, pizzas and pies, desserts, and carbonated beverages and juices. This pattern was accompanied by elevated intake of energy and fat notably saturated fats, sugars and negatively correlated with intake of proteins and fibers. The excess consumption of the energy dense foods is likely to contribute to a surplus intake of energy which in turn is linked to a higher prevalence of overweight/obesity and related chronic diseases 
Table 4 Correlates of the identified dietary patterns in the study population as assessed by multivariate linear regression

\begin{tabular}{|c|c|c|c|c|c|c|}
\hline \multirow[t]{2}{*}{ Sociodemographic and lifestyle characteristic } & \multicolumn{2}{|c|}{ Fast food/dessert } & \multicolumn{2}{|c|}{ Traditional Lebanese pattern } & \multicolumn{2}{|c|}{ High protein pattern } \\
\hline & $\beta$ & $95 \% \mathrm{CI}$ & $\beta$ & $95 \% \mathrm{CI}$ & $\beta$ & $95 \% \mathrm{CI}$ \\
\hline Age & -0.03 & $(-0.05)-(-0.01)$ & 0.10 & $0.01-0.32$ & 0.01 & $(-0.02)-0.04$ \\
\hline Males versus females & 0.60 & $0.14-1.06$ & 0.06 & $(-0.12)-1.14$ & -0.09 & $(-0.79)-0.61$ \\
\hline Crowding index & 0.51 & $0.16-0.87$ & 0.02 & $(-0.37)-0.41$ & -0.23 & $(-0.77)-0.31$ \\
\hline Education & 0.17 & $(-0.08)-0.43$ & -0.11 & $(-0.39)-0.17$ & 0.11 & $(-0.27)-0.50$ \\
\hline Married versus unmarried & -0.09 & $(-0.53)-0.35$ & -0.05 & $(-0.54)-0.44$ & -0.38 & $(-1.05)-0.29$ \\
\hline Smokers versus non-smokers & 0.38 & $(-0.09)-0.84$ & -0.18 & $(-0.69)-0.34$ & -0.78 & $(-1.48)-(-0.07)$ \\
\hline Existence of family history of obesity & -0.03 & $(-0.42)-0.35$ & 0.03 & $(-0.39)-0.46$ & -0.16 & $(-0.75)-0.42$ \\
\hline Physical activity & 0.09 & $(-0.12)-0.30$ & 0.00 & $(-0.24)-0.24$ & 0.43 & $0.11-0.76$ \\
\hline Breakfast consumption per week & -0.06 & $(-0.14)-0.01$ & 0.03 & $(-0.05)-0.11$ & 0.06 & $(-0.05)-0.17$ \\
\hline Snack consumption per day & 0.44 & $0.23-0.66$ & 0.28 & $0.04-0.52$ & 0.21 & $(-0.12)-0.54$ \\
\hline Eating at TV weekly & 0.02 & $(-0.04)-0.08$ & -0.02 & $(-0.09)-0.05$ & -0.03 & $(-0.12)-0.07$ \\
\hline Frequency of eating out per week & -0.02 & $(-0.08)-0.05$ & -0.07 & $(-0.14)-.01$ & 0.11 & $0.01-0.21$ \\
\hline
\end{tabular}

Values presented in this table are linear regression coefficients and their corresponding $95 \%$ confidence intervals

Table 5 Odds of metabolic abnormalities and MetS across quintiles of factor scores as assessed by multivariate-adjusted logistic regression in the study population $(n=323)$

\begin{tabular}{|c|c|c|c|c|c|c|}
\hline & $\begin{array}{l}\text { Elevated waist } \\
\text { circumference }^{\mathrm{a}}\end{array}$ & $\begin{array}{l}\text { Hyper } \\
\text { Triglyceridemia }{ }^{\mathrm{b}}\end{array}$ & HDL-C ${ }^{\mathrm{c}}$ & Hypertension $^{\mathrm{d}}$ & Hyperglycemia $^{\mathrm{e}}$ & $\begin{array}{l}\text { Metabolic } \\
\text { syndrome }^{f}\end{array}$ \\
\hline \multicolumn{7}{|c|}{ Fast food/dessert } \\
\hline 1st quintile & 1.00 & 1.00 & 1.00 & 1.00 & 1.00 & 1.00 \\
\hline 3rd quintile & $0.98(0.47-2.13)$ & $1.18(0.52-2.70)$ & $1.82(0.82-4.03)$ & $0.84(0.38-1.82)$ & $1.56(0.70-3.47)$ & $1.64(0.75-3.59)$ \\
\hline 5th quintile & $1.70(0.31-2.58)$ & $2.01(0.84-4.74)$ & $1.32(0.56-3.12)$ & $1.40(0.62-3.17)$ & $3.81(1.59-9.14)$ & $3.13(1.36-7.22)$ \\
\hline$p$ for trend $d^{g}$ & 0.30 & 0.20 & 0.67 & 0.183 & 0.001 & 0.06 \\
\hline \multicolumn{7}{|c|}{ Traditional lebanese } \\
\hline 1st quintile & 1.00 & 1.00 & 1.00 & 1.00 & 1.00 & 1.00 \\
\hline 3rd quintile & $0.86(0.41-1.81)$ & $0.85(0.38-1.88)$ & $1.83(0.82-4.09)$ & $1.54(0.69-3.43)$ & $1.60(0.74-3.43)$ & $1.55(0.70-3.43)$ \\
\hline 5th quintile & $1.07(0.51-2.24)$ & $1.28(0.59-2.79)$ & $1.77(0.80-3.93)$ & $2.31(0.91-6.74)$ & $1.44(0.67-3.08)$ & $1.96(0.82-4.34)$ \\
\hline$p$ for trend & 0.83 & 0.42 & 0.32 & $<0.001$ & 0.31 & 0.10 \\
\hline \multicolumn{7}{|l|}{ High protein } \\
\hline 1st quintile & 1.00 & 1.00 & 1.00 & 1.00 & 1.00 & 1.00 \\
\hline 3rd quintile & $1.76(0.82-3.83)$ & $1.21(0.55-2.64)$ & $1.18(0.54-2.57)$ & $1.99(0.85-4.63)$ & $1.13(0.52-2.46)$ & $0.90(0.41-1.99)$ \\
\hline 5th quintile & $1.74(0.79-3.85)$ & $1.02(0.46-2.27)$ & $0.60(0.30-1.38)$ & $2.98(1.26-7.02)$ & $1.60(0.70-3.62)$ & $1.22(0.54-2.77)$ \\
\hline$p$ for trend & 0.25 & 0.91 & 0.45 & 0.01 & 0.70 & 0.76 \\
\hline
\end{tabular}

Values presented in this table are OR and 95\% CI. OR were adjusted for age, sex, marital status, education, crowding index, physical activity, and smoking

${ }^{a}$ WC: Males $>94 \mathrm{~cm}$, Females $>80 \mathrm{~cm}$

b Serum triacylglycerols $>150 \mathrm{mg} / \mathrm{dL}$

${ }^{c}$ HDL-C: Males $<50 \mathrm{mg} / \mathrm{dl}$, Females $<40 \mathrm{mg} / \mathrm{dL}$

${ }^{\mathrm{d}}$ Hypertension: Systolic $\geq 130$ and/or diastolic $\geq 85 \mathrm{~mm} \mathrm{Hg}$

${ }^{\text {e }}$ Hyperglycemia: Fasting blood sugar $\geq 100 \mathrm{mg} / \mathrm{dL}$

${ }^{\mathrm{f}}$ IDF definition of metabolic syndrome [2]

g $p$ trend using the median factor score for each quintile

over time [18]. Furthermore, high consumption of sweetened beverages and desserts has been independently associated with MetS [19]. Desserts, which are foods with high glycemic index, are also associated with higher risk of MetS [20]. With the exception of red meat and dairy products, the Fast Food/Dessert pattern contains most of 
the food groups of the Western pattern identified in previous studies (e.g. sweets, desserts, fast foods, and sweetened beverages) [21-23]. The Western pattern was shown to be adversely associated with incident MetS in the prospective Atherosclerosis Risk in Communities Study [24]. Another recent study in an urban Mexican population showed that consumption of a Western pattern was associated with $50 \%$ increase in the risk of MetS [25].

The traditional Lebanese pattern identified in this study was not associated with the MetS and its metabolic abnormalities. The Traditional Lebanese pattern is generally considered a Mediterranean pattern; however, it is important to note that Mediterranean diets may be different from one country to the other among the countries of the Mediterranean basin [26]. This pattern is highly loaded on fruits and vegetables which are likely to associate negatively with the risk of MetS. However, some energy dense foods as whole dairy products and traditional sweets were also heavily consumed in this dietary pattern and may have counteracted the protective effects of fruits and vegetables might have had on MetS. Consumption of sweets has its historical roots in the abundant usage of honey (an important element of the Mediterranean diet) that is currently replaced by the extensive use of corn syrup and sucrose in the making of many traditional sweets.

We also found that subjects who belonged to the fifth quintile of the High Protein pattern had higher blood pressure compared to those in the lowest quintile. While fish and particularly omega 3 fatty acids consumption was repeatedly reported in the literature to exert a protective effect against hypertension and MetS [27], the evidence regarding the association between red meat intake and MetS is less consistent [28-30]. This controversy in the literature could be due to the various types of meats included in the "High Protein" or "meatbased" patterns and their methods of preparation. In our study, the High Protein dietary pattern included cured meat that are known to be high in salt content and might have contributed to elevated blood pressure among consumers.

The associations between the dietary patterns identified in this study and the sociodemographic characteristics of participants were in accordance with the literature. Our results showed that younger age and male gender were more likely to adhere to the Fast Food/Dessert [31, 32]. Crowding index was also positively associated with this dietary pattern. This is consistent with previous research reporting that the "unhealthy pattern" is associated with a lower socioeconomic status $[33,34]$. The general observed socioeconomic nutritional gradient can be mediated by food costs, meaning that lowest cost diets mainly consumed by the lowest socioeconomic positions are generally unhealthy. People, who have less money, choose to buy cheaper foods, and these cheaper foods are less healthy [35].

Few limitations should be considered when interpreting the study findings. First, the percentage of survey participants who agreed to give blood (respondents) was low $(24.3 \%)$. However, respondents and non-respondents were comparable across the sociodemographic characteristics except for marital status (62\% of respondents vs. $50 \%$ of non-respondents are married) (data not shown). In addition, the dietary data of non-respondents were analyzed, and factor loading matrices were compared between respondents and non-respondents. All food groups with factor loadings greater than 0.4 loaded similarly on the three identified patterns in the two matrices. Minor differences were noted for few food groups with factor loadings lower than 0.4 and which included butter, alcoholic beverages, and hot drinks ("Appendix 2"). Second, this is a cross-sectional study, and its findings can mainly be used to test associations rather than assessing causal relationships. It remains important to note that the food frequency questionnaire used in this study was not validated in our study population. The fact that the food frequency questionnaire was administered by a trained dietitian and not self-completed offers many advantages in that it does not require a literate population and results in consistent interpretations and higher response and completion rates, each of which may enhance the validity of the data [36, 37].

\section{Conclusion}

Our results suggested that a Fast Food/Dessert type of diet is associated with higher likelihood of MetS, hypertension, and hyperglycemia, while a diet high in meat, poultry, and fish was associated with an elevated blood pressure. These findings lay grounds for planning intervention strategies that are culture based and in line with local dietary habits.

Acknowledgments The study was funded by the Training Programs in Epidemiology and Public Health Interventions Network (TEPHINET). Additional funds were contributed by the World Health Organization (WHO-Lebanon) and the Lebanese National Council for Scientific Research (LNCSR). Funders had no role in the study design, data collection, analysis, interpretation and reporting, and in the decision to submit the paper for publication.

Conflict of interest All authors have no conflict of interest.

Open Access This article is distributed under the terms of the Creative Commons Attribution Noncommercial License which permits any noncommercial use, distribution, and reproduction in any medium, provided the original author(s) and source are credited. 


\section{Appendix 1}

See Table 6.

Table 6 Food groupings used in the dietary pattern analysis

\begin{tabular}{|c|c|}
\hline Food group & Components \\
\hline Alcoholic beverages & Non-wine alcoholic beverages, beer, wine \\
\hline Traditional sweets & $\begin{array}{l}\text { All kinds of traditional sweets including } \\
\text { baklava, ma'amoul, knafeh, and traditional } \\
\text { ice cream }\end{array}$ \\
\hline Breakfast cereals & Regular corn flakes \\
\hline Butter & Butter and ghee \\
\hline $\begin{array}{l}\text { Carbonated } \\
\text { beverages and } \\
\text { juices }\end{array}$ & Sodas and all kinds of bottled juices \\
\hline Chawarma & Chawarma sandwiches \\
\hline Chicken & $\begin{array}{l}\text { All kinds of poultry (broiled, fried, and } \\
\text { boiled) }\end{array}$ \\
\hline $\begin{array}{l}\text { Dairy products-low } \\
\text { fat }\end{array}$ & $\begin{array}{l}\text { Half-skimmed milk, low-fat cheese, low-fat } \\
\text { yogurt }\end{array}$ \\
\hline Dairy products-full & $\begin{array}{l}\text { Whole milk, whole-fat cheese, lebneh, } \\
\text { whole-fat yogurt. }\end{array}$ \\
\hline Desserts & $\begin{array}{l}\text { Cakes, cookies, muffin, doughnut, honey, } \\
\text { jams, chocolate. }\end{array}$ \\
\hline Eggs & Eggs both boiled and fried \\
\hline Falafel & Falafel sandwiches \\
\hline Fish & Fish both fried and broiled \\
\hline Fruits & $\begin{array}{l}\text { Deep yellow orange fruits, bananas and } \\
\text { apples, strawberries, citrus fruits, grapes, } \\
\text { fresh fruit juices }\end{array}$ \\
\hline Grains & $\begin{array}{l}\text { Bread whole and refined, rice and rice } \\
\text { products, pasta, crushed parboiled wheat }\end{array}$ \\
\hline Hamburger & All types of hamburger sandwiches \\
\hline Hot drinks & Turkish coffee, instant coffee, cocoa, and tea \\
\hline Legumes & $\begin{array}{l}\text { All kinds of legumes like beans, lentils, } \\
\text { chickpeas, fava beans, and peas }\end{array}$ \\
\hline Mayonnaise & $\begin{array}{l}\text { All kinds of mayonnaise and mayonnaise- } \\
\text { based salad dressing }\end{array}$ \\
\hline Meat & $\begin{array}{l}\text { Ovine, caprine, suine, and bovine meats, } \\
\text { except for shawarma }\end{array}$ \\
\hline Nuts and dried fruits & $\begin{array}{l}\text { Nuts, both raw and roasted, dried raisin, } \\
\text { prunes, and apricots }\end{array}$ \\
\hline Olives & All kinds of pickled olives \\
\hline Pizza and pies & $\begin{array}{l}\text { Pizza, manaeesh with cheese, and thyme } \\
\text { (manaeesh is the Lebanese version of the } \\
\text { pizza dough) }\end{array}$ \\
\hline Vegetable oil & Vegetable oil \\
\hline Vegetables & $\begin{array}{l}\text { Dark green and yellow vegetables, tomato, } \\
\text { salad season, zucchini and eggplant, } \\
\text { cauliflower, and potato }\end{array}$ \\
\hline
\end{tabular}

\section{Appendix 2}

See Table 7.

Table 7 Factor loading matrices for the three identified patterns among respondents $(n=323)$ and non-respondents $(n=1008)$

\begin{tabular}{|c|c|c|c|c|c|c|}
\hline & \multicolumn{3}{|c|}{ Respondents } & \multicolumn{3}{|c|}{ Non-respondents } \\
\hline & $\begin{array}{l}\text { Fast } \\
\text { food/ } \\
\text { dessert }\end{array}$ & $\begin{array}{l}\text { Traditional } \\
\text { Lebanese }\end{array}$ & $\begin{array}{l}\text { High } \\
\text { protein }\end{array}$ & $\begin{array}{l}\text { Fast } \\
\text { food/ } \\
\text { dessert }\end{array}$ & $\begin{array}{l}\text { Traditional } \\
\text { Lebanese }\end{array}$ & $\begin{array}{l}\text { High } \\
\text { protein }\end{array}$ \\
\hline Hamburger & 0.76 & - & - & 0.55 & - & - \\
\hline Chawarma & 0.72 & - & - & 0.85 & - & - \\
\hline Pizza and pies & 0.70 & - & - & 0.39 & - & - \\
\hline $\begin{array}{l}\text { Falafel } \\
\text { Sandwiches }\end{array}$ & 0.61 & - & - & 0.83 & - & - \\
\hline Desserts & 0.41 & 0.23 & - & 0.59 & - & - \\
\hline $\begin{array}{c}\text { Carbonated } \\
\text { beverages } \\
\text { and juices }\end{array}$ & 0.40 & - & - & 0.35 & - & - \\
\hline Mayonnaise & 0.35 & - & - & 0.67 & - & - \\
\hline Butter & 0.22 & - & - & 0.21 & 0.33 & - \\
\hline $\begin{array}{l}\text { Alcoholic } \\
\text { beverages }\end{array}$ & 0.20 & - & - & - & 0.21 & - \\
\hline $\begin{array}{l}\text { Dairy products- } \\
\text { full fat }\end{array}$ & - & 0.58 & - & - & 0.46 & - \\
\hline Olives & - & 0.56 & - & - & 0.56 & - \\
\hline Fruits & -0.22 & 0.49 & 0.21 & - & 0.42 & \\
\hline Legumes & & 0.47 & - & - & 0.36 & - \\
\hline Grains & 0.27 & 0.47 & - & - & 0.65 & - \\
\hline Eggs & 0.21 & 0.45 & - & - & 0.35 & - \\
\hline Vegetable oil & - & 0.43 & - & - & 0.33 & - \\
\hline $\begin{array}{l}\text { Nuts and dried } \\
\text { fruits }\end{array}$ & 0.27 & 0.40 & - & - & 0.39 & - \\
\hline $\begin{array}{l}\text { Traditional } \\
\text { sweets }\end{array}$ & - & 0.37 & - & - & 0.34 & - \\
\hline Vegetables & - & 0.34 & - & - & 0.26 & - \\
\hline Fish & - & - & 0.70 & - & - & 0.23 \\
\hline Chicken & 0.21 & - & 0.69 & - & - & 0.69 \\
\hline Meat & 0.22 & - & 0.60 & - & - & 0.61 \\
\hline $\begin{array}{l}\text { Dairy products- } \\
\text { low fat }\end{array}$ & - & -0.29 & 0.54 & - & - & 0.25 \\
\hline $\begin{array}{c}\text { Breakfast } \\
\text { cereals }\end{array}$ & - & - & 0.23 & - & - & 0.24 \\
\hline Hot drinks & - & - & - & - & 0.23 & - \\
\hline $\begin{array}{l}\text { Percent } \\
\text { variance } \\
\text { explained by } \\
\text { each pattern }\end{array}$ & 13.11 & 9.71 & 7.80 & 15.56 & 7.44 & 6.43 \\
\hline
\end{tabular}

Factor loadings of less than 10.21 were not listed in the table for simplicity. Loadings $\geq 0.3$ are bolded 


\section{References}

1. Reaven GM (1988) Banting lecture 1988. Role of insulin resistance in human disease. Diabetes 37(12):1595-1607

2. Alberti KG, Eckel RH, Grundy SM, Zimmet PZ, Cleeman JI, Donato KA, Fruchart JC, James WP, Loria CM et al (2009) Harmonizing the metabolic syndrome: a joint interim statement of the international diabetes federation task force on epidemiology and prevention; National Heart, Lung, and Blood Institute; American Heart Association; World Heart Federation; International Atherosclerosis Society; and International Association for the study of Obesity. Circulation 120(16):1640-1645

3. Chedid R, Gannage-Yared MH, Khalife S, Halaby G, Zoghbi F (2009) Impact of different metabolic syndrome classifications on the metabolic syndrome prevalence in a young Middle Eastern Population. Metabolism 58(6):746-752

4. Sibai A, Obeid O, Batal M, Adra N, El Khoury D, Hwalla N (2008) Prevalence and correlates of metabolic syndrome in an adult Lebanese population. CVD Prev Control 3(2):83

5. Jebb SA, Lovegrove JA, Griffin BA, Frost GS, Moore CS, Chatfield MD, Bluck LJ, Williams CM, Sanders TA, on behalf of the RISCK Study Group (2010) Effect of changing the amount and type of fat and carbohydrate on insulin sensitivity and cardiovascular risk: the RISCK (reading, imperial, surrey, cambridge, and kings) trial. Am J Clin Nutr 92:748-758

6. Montegaard C, Tulk HM, Lauritzen L, Tholstrup T, Robinson LE (2010) Acute ingestion of long-chain (n-3) polyunsaturated fatty acids decreases fibrinolysis in men with metabolic syndrome. J Nutr 140(1):38-43

7. Hu FB (2002) Dietary pattern analysis: a new direction in nutritional epidemiology. Curr Opin Lipidol 13(1):3-9

8. Jacques PF, Tucker KL (2001) Are dietary patterns useful for understanding the role of diet in chronic disease? Am J Clin Nutr 73(1):1-2

9. Panagiotakos DB, Pitsavos C, Skoumas Y, Stefanadis C (2007) The association between food patterns and the metabolic syndrome using principal components analysis: the ATTICA study. J Am Diet Assoc 107(6):979, 87; quiz 997

10. Leite ML, Nicolosi A (2009) Dietary patterns and metabolic syndrome factors in a non-diabetic Italian population. Public Health Nutr 12(9):1494-1503

11. DiBello JR, McGarvey ST, Kraft P, Goldberg R, Campos H, Quested C, Laumoli TS, Baylin A (2009) Dietary patterns are associated with metabolic syndrome in adult Samoans. J Nutr 139(10):1933-1943

12. Song Y, Joung H (2010) A traditional Korean dietary pattern and metabolic syndrome abnormalities. Nutr Metab Cardiovasc Dis. doi:10.1016/j.numecd.2010.09.002

13. The WHO STEPwise approach to chronic disease risk factor surveillance (STEPS). http://www.who.int/chp/steps/en/. Accessed Dec 2010

14. IPAQ (2005) IPAQ international physical activity questionnaire. Guidelines for data processing and analysis (IPAQ). Short forms and long forms

15. Nutritionist IV (1993) N-squared computing. Nutritionist IV, Silverton

16. Willett W, Howe GR, Kushi LH (1997) Adjustment for total energy intake in epidemiologic studies. Am J Clin Nutr 65:1220S

17. SPSS (2003) Statistical package for windows. 14.1

18. Dietary guidelines for Americans (2005) http://www.health.gov/ dietaryguidelines/dga2005/document/default.htm. Accessed Dec 2010

19. Elliott SS, Keim NL, Stern JS, Teff K, Havel PJ (2002) Fructose, weight gain, and the insulin resistance syndrome. Am J Clin Nutr 76(5):911-922
20. Ludwig DS (2002) The glycemic index: physiological mechanisms relating to obesity, diabetes, and cardiovascular disease. JAMA 287(18):2414-2423

21. Fung TT, Rimm EB, Spiegelman D, Rifai N, Tofler GH, Willett WC, Hu FB (2001) Association between dietary patterns and plasma biomarkers of obesity and cardiovascular disease risk. Am J Clin Nutr 73(1):61-67

22. Paradis AM, Pérusse L, Vohl MC (2006) Dietary patterns and associated lifestyles in individuals with and without familial history of obesity: a cross-sectional study. Int J Behav Nutr Phys Act 3:38

23. Schulze MB, Fung TT, Manson JE, Willett WC, Hu FB (2006) Dietary patterns and changes in body weight in women. Obesity (Silver Spring) 14(8):1444-1453

24. Lutsey PL, Steffen LM, Stevens J (2008) Dietary intake and the development of the metabolic syndrome: the Atherosclerosis Risk in Communities Study. Circulation 117(6):754-761

25. Denova-Gutiérrez E, Castañón S, Talavera JO, Gallegos-Carrillo K, Flores M, Dosamantes-Carrasco D, Willett WC, Salmerón J (2010) Dietary patterns are associated with metabolic syndrome in an urban Mexican population. J Nutr 140(10):1855-1863. Epub 2010 Aug 11

26. Kastorini CM, Milionis HJ, Esposito K, Guigliano D, Gougevenos JA, Panangiotakos DB et al (2011) The effect of Mediterranean diet on Metabolic syndrome and its components: a metaanalysis of 50 studies and 534, 906 individuals. J Am Coll Cardiol 57(11):1299-1313

27. Abeywardena MY, Patten GS (2011) Role of $\omega 3$ Longchain polyunsaturated fatty acids in reducing cardio-metabolic risk factors. Endocr Metab Immune Disord Drug Targets. 2011 Jun 8

28. Wang L, Manson JE, Buring JE, Sesso HD (2008) Meat intake and the risk of hypertension in middle-aged and older women. J Hypertens 26(2):215-222

29. Metintas S, Arikan I, Kalyoncu C (2009) Awareness of hypertension and other cardiovascular risk factors in rural and urban areas in Turkey. Trans R Soc Trop Med Hyg 103(8):812-818

30. Nkondjock A, Bizome E (2010) Dietary patterns associated with hypertension prevalence in the Cameroon defense forces. Eur $\mathbf{J}$ Clin Nutr 64(9):1014-1021

31. Fung TT, Schulze M, Manson JE, Willett WC, Hu FB (2004) Dietary patterns, meat intake, and the risk of type 2 diabetes in women. Arch Intern Med 164(20):2235-2240

32. Rezazadeh A, Rashidkhani B, Omidvar N (2010) Association of major dietary patterns with socioeconomic and lifestyle factors of adult women living in Tehran, Iran. Nutrition 26(3):337-341

33. Schulze MB, Hoffmann K, Kroke A, Boeing H (2001) Dietary patterns and their association with food and nutrient intake in the European Prospective Investigation into Cancer and Nutrition (EPIC)-potsdam study. Br J Nutr 85(3):363-373

34. Park SY, Murphy SP, Wilkens LR, Yamamoto JF, Sharma S, Hankin JH, Henderson BE, Kolonel LN (2005) Dietary patterns using the food guide pyramid groups are associated with sociodemographic and lifestyle factors: the multiethnic cohort study. J Nutr 135(4):843-849

35. Mullie P, Clarys P, Hulens M, Vansant G (2010) Dietary patterns and socioeconomic position. Eur J Clin Nutr 64(3):231-238

36. Willet W (1998) Nutritional epidemiology, 2nd edn. Oxford University Press, New York

37. Hu FB, Rimm E, Smith-Warner SA, Feskanich D, Stampfer MJ, Ascherio A, Sampson L, Willett WC (1999) Reproducibility and validity of dietary patterns assessed with a food-frequency questionnaire. Am J Clin Nutr 69(2):243-249 